\title{
Paisagem socioambiental coletiva: experiências ecosóficas com mulheres rurais
}

Collective socio-environmental landscape: ecosophical experiences with rural women

\author{
Viviane Röhrs $₫(\mathbb{D}$, Jane Márcia Mazzarino* $\square(\mathbb{D}$ \\ Universidade do Vale do Taquari, Lajeado, Rio Grande do Sul, Brasil \\ E-mail: janemazzarino@gmail.com \\ *E-mail para correspondência: vivirohrs@gmail.com
}

Recebido (Received): 17/11/2020

Aceito (Accepted): 10/09/2021

Resumo: O objetivo do estudo é investigar alterações nas relações das mulheres rurais com a paisagem socioambiental por meio de metodologias de caráter participativo, provocadoras de experiências, a fim de analisar a emergência de uma paisagem socioambiental ecosófica coletiva. Utilizou-se como método a pesquisa-intervenção, apoiada em estudos bibliográfico, documental e de campo. A pesquisa de campo compreendeu vivências junto à natureza e entrevistas individuais e grupais, além da observação direta. Como resultados evidenciamos a emergência de paisagens socioambientais individuais e coletivas mediadas pelas três ecologias propostas pela perspectiva ecosófica. As vivências fortaleceram as relações das mulheres rurais consigo mesmas, com o ambiente onde vivem e com as pessoas que convivem.

Palavras chave: Intervenções; ecologia; subjetividade; relações sociais; relação com o ambiente.

Abstract: The objective of the study is to investigate changes in the relations of rural women with the socioenvironmental landscape through participatory methodologies, provoking experiences, in order to analyze the emergence of a collective eco-environmental socio-environmental landscape. Intervention research was used as method, supported by bibliographic, documentary and field studies. The field research included experiences with nature and individual and group interviews, in addition to direct observation. As a result, we highlight the emergence of individual and collective socio-environmental landscapes mediated by the three ecologies proposed by the ecosystem perspective. The experiences strengthened rural women's relationships with themselves, with the environment where they live and with the people they live with.

Kaywords: Interventions; ecology; subjectivity; social relations; relationship with the environment.

\section{Introdução}

A desconectividade humana e socioambiental que se configura na sociedade atual precisa ser reconhecida pelos sujeitos, a fim de que sejam criadas novas formas de ver e se relacionar com e no mundo. Esta pesquisa aposta no contato humano com o mundo natural, com este sendo experienciado de modo envolvente e sensibilizador, investindo-se no seu potencial transformador. Uma proposta de reconexão foi colocada em prática por meio de oito encontros vivenciais e reflexivos com nove mulheres rurais que foram provocadas a olhar para si, para o outro e para o mundo.

Sob influência de Guattari, considera-se necessário pensar nestes três tipos de relações que nos compõem. Guattari (1990) defende que a articulação destas três esferas - do meio ambiente, das relações sociais e da subjetividade humana, que ele denomina de três ecologias - é imprescindível para provocar experiências que ampliem os sentidos. Sua proposta, denominada de ecosofia, refere-se à intenção de reinventar as formas de "ser em grupo", consigo e com o ambiente. Assim, toma-se como conceito de paisagem socioambiental neste trabalho aquela que é constituída pelas relações entre as três ecologias. A partir desta perspectiva, que é inédita, a intenção é compreender como a pesquisa-intervenção pode afetar as relações das mulheres rurais consigo, com o outro e com o ambiente, constituindo paisagens socioambientais coletivas?

Entende-se que as relações cotidianas no ambiente de vida vão tecendo redes de significados, assim, novas tessituras foram provocadas por meio de processos de educação ambiental direcionados para as mulheres rurais. Potencializaram-se as relações subjetivas, sociais e ambientais no contexto rural por meio 
das metodologias participativas, buscando-se compreender como estas metodologias podem trazer à tona sentimentos e laços afetivos com o meio onde as mulheres encontram-se inseridas.

A pesquisa é de cunho intervencionista, apoiada em estudo bibliográfico, documental e de campo. O estudo delimita-se a um grupo formado por nove mulheres rurais do município de Lagoão, localizado na mesorregião Noroeste Rio-Grandense, atendidas pela Emater/RS-Ascar. A coleta de dados a campo foi realizada no segundo semestre de 2019, e incluiu as intervenções, observações diretas e entrevistas individuais e em grupo.

O objetivo do estudo é investigar alterações nas relações das mulheres rurais com a paisagem socioambiental por meio de metodologias de caráter participativo, provocadoras de experiências, a fim de analisar a emergência de uma paisagem socioambiental ecosófica coletiva.

\section{Referencial teórico}

\subsection{Paisagens socioambientais coletivas ecosóficas}

Entende-se a paisagem socioambiental como uma formação triádica, constituída pelas relações criadas entre subjetividade humana, relações sociais e com o ambiente, existentes e/ou provocadas por experiências que ampliam os sentidos, de modo a possibilitar a reinvenção de formas de ser e se expressar no mundo. Portanto, propomos que tal paisagem socioambiental seja definida como ecosófica, já que adotamos o conceito de ecosofia de Guattari (1990), o qual mistura-se às propostas teóricas sobre a experiência, de Bondía (2002) e paisagem de Tuan (1983).

A paisagem socioambiental ecosófica, neste estudo, será investigada como uma prática coletiva, decorrente dos encontros entre as relações triádicas de cada uma das nove mulheres participantes da experiência de sensibilização ambiental, provocada pelas pesquisadoras. Portanto, o que se fez foi mapear esta paisagem socioambiental coletiva levando-se em conta aspectos ecológicos, sociais e da psique, os quais são ressaltados pelos autores que colocam-se para estudar as paisagens, especialmente a partir da geografia humana.

Compreender a constituição de paisagens a partir do âmbito humano é adotar uma perspectiva socioambiental. Segundo Loureiro (2004), o termo socioambiental é usado para evidenciar todas as relações que se dão em sociedade em um determinado ambiente de nosso planeta. Na visão deste autor, o socioambiental abrange não apenas a visão estática de sociedade/ambiente, mas também aspectos como o cultural, o político, o econômico, o ideológico, os valores éticos e morais. Além disso, entende-se que cada experiência de vida é perpassada por relações afetivas, sociais e ambientais. No âmbito rural, o qual Gomes, Nogueira e Toneli (2016) definem como "espaço de representação e de ação", há especificidades. O espaço/tempo/lugar rural difere de outros. A proximidade com a natureza é ampliada, e, por ser cotidiana, muitas vezes constitui o próprio modo de ser, viver e fazer.

$\mathrm{O}$ espaço, na medida em que adquire significado e definição, vai se transformando em lugar. Para Tuan (1983), "na imaginação é fácil tratar espaço, tempo e lugar separadamente. Na experiência vivida eles estão indissoluvelmente ligados" (TUAN, 1983, p. 5). Quanto mais as pessoas permanecem em determinado lugar, mais se apegam a ele, desenvolvendo sentimentos afetivos, criando laços integrativos influenciados pela pela cultura e/ou criados por meio de seus valores e experiências de vida. "O lugar pode adquirir profundo significado para o adulto através do contínuo acréscimo de sentimento ao longo dos anos" (TUAN, 1983, p. $37)$.

Segundo o autor, o espaço relaciona-se com o abstrato e o lugar com o que é concreto, pois o lugar é definido pelas coisas materiais e vivências dentro de um determinado espaço, que é mais abstrato; o lugar é onde se encontram os objetos e onde estes criam vidas por intermédio de seus autores/atores. "Espaço e lugar são termos familiares e complementares: o que começa como espaço indiferenciado acaba assumindo a configuração de lugar, ao conhecermos e o dotarmos de valor" (TUAN, 1983, p. 148).

Espaço não é simplesmente uma ideia, mas um conjunto complexo de ideias onde diferentes sujeitos o caracterizam conforme sua necessidade ambiental, cultural e social. É no dia a dia do espaço que as ações humanas acontecem, e essas ações vão muito além de utilizar o espaço como uma simples orientação, elas levam em conta as vivências sociais e culturais de cada indivíduo, pois "tempo e espaço são estruturados em torno da intencionalidade e da atividade" (TUAN, 1983, p. 9).

Já para Cabral (2007) “[...] o espaço em si pode ser primordialmente dado, mas sua organização e sentido são produtos da transformação e de experiências sociais" (CABRAL, 2007, p. 145). Não há como dissociar espaço, lugar e tempo, pois estão concomitantemente alinhados em uma mesma dimensão, a qual está 
relacionada às experiências vividas, onde o material e o social fazem sentido juntos. Cada história vivenciada dá significação a um determinado lugar, num determinado espaço em um determinado período de tempo.

Nesse sentido, para Cabral (2007, p. 150), "a paisagem percebida é também significada e construída", pois cada indivíduo, cada "povo" faz sua própria leitura em uma determinada paisagem, enfatizando sua significação conforme sua vivência. Assim, "a paisagem pode ser considerada um texto que serve a uma multiplicidade de leituras" (TUAN, 1983, p. 150). A paisagem é tudo aquilo que vemos, diz o autor. Ela se constitui a partir da presença em diferentes escalas dos elementos naturais e culturais, sobre os quais a sociedade interage e cuja percepção permite a leitura do espectador. E cada espectador tem a sua forma de ver o mundo, o que faz com que uma determinada paisagem vista aos olhos de um indivíduo, pode não ser a mesma vista por outro. E assim as paisagens vão se construindo, numa lógica humanística, sob perspectivas ambientais, sociais e culturais, onde traços afetivos se fortalecem e caracterizam "aquele espaço", "aquele lugar" e "aquela percepção da paisagem", ao longo do tempo. Para Sauer (1998) para entender uma cultura, o modo de vida de um povo, é necessário primeiro conhecer a paisagem natural, pois a paisagem cultural é decorrente das transformações causadas pelo homem na natureza.

Uma paisagem transmite funcionalidades, significados, ideias e valores, e, assim, projeta uma imagem em movimento, já que o ser humano muda os elementos naturais de lugar, transformando-os, segundo Salvador (2008). Da mesma forma, ele mesmo muda de lugar, transformando a si mesmo, mudando a sua própria maneira de enxergar o ambiente e nele colocar-se. Portanto, como diz Monbeig (2005), a paisagem é aquilo que se vive, é também história em movimento.

As funcionalidades se apresentam através das relações simbólicas entre os elementos naturais e humanos que vão sendo significadas ao longo do tempo, formando uma paisagem que, além de portadora de significado, expressa valores, crenças, mitos e utopias (CORRÊA; ROSENDAHL, 1998, p.8). O simbolismo da paisagem é formado a partir do momento que a vemos como uma dimensão social. Assim, fica impossível isentarmos o ser humano de uma paisagem geográfica, sabendo que ali, ele faz história. Portanto, as paisagens são formadas por meio de modos de apropriação e transformação do ambiente pelo homem (COSGROVE, 1998). A funcionalidade dos elementos que permeiam uma paisagem determina seu simbolismo e, assim, as relações com a paisagem.

Uma paisagem é sempre uma paisagem vivida, pois a vivência de cada pessoa em determinada paisagem é impregnada de sua subjetividade, de seus sonhos e de suas emoções. Como acentua Oliveira (2000, p. 19), "[...] a paisagem é um espaço de cada ser humano, um espaço individualizado". Nesse espaço individualizado, segundo a autora, podemos explorar melhor as interações entre o ser humano e o meio ambiente. $\mathrm{O}$ contexto da interação se dará pelas circunstâncias em que o sujeito ali fará sua atuação, como ele experiência e dá significados à paisagem. Em grupo é possível mapear uma paisagem coletiva, constituída das ressonâncias entre as participantes, constituída pelos encontros de sentidos dados às paisagens vividas por cada um, de modo singular.

\subsection{A paisagem como experiência estética}

Para entender o mundo e para melhor comunicar-se com o ambiente que o rodeia, o sujeito necessita de todos os sentidos: "uns sentidos suprindo os outros, uns se destacando sobre os outros" (OLIVEIRA, 2000, p. 21). Pelos órgãos dos sentidos, se acessam os estímulos externos do ambiente e, com eles, pode-se ou não produzir uma paisagem mais profunda sobre si mesmo ou sobre o meio em que vive, de forma individual ou coletiva, porque nem sempre o sujeito está aberto para o encontro com os elementos sensibilizadores externos (cheiros, sons, imagens, por exemplo). "Falar de paisagem é falar de nós mesmos", diz Carvalho (2011, p.38), pois a paisagem é determinada pelos valores atribuídos pelos sujeitos que nela fazem história. E esta é uma construção coletiva.

A diversidade de paisagens construídas faz com que, na complexa sociedade moderna, os gostos individuais por ambientes naturais variem enormemente. Não se pode definir um jeito ou um gosto de relacionar-se com a paisagem física.

As mais intensas experiências estéticas da natureza possivelmente nos apanham de surpresa. A beleza é sentida, como o contato repentino com um aspecto da realidade até então desconhecido; é a antítese do gosto desenvolvido por certas paisagens ou o sentimento afetivo por lugares que se conhece bem (TUAN, 1980, p. 108).

Entende-se que a experiência estética de uma mulher rural com a natureza é peculiar. Para Tuan o apego à terra do pequeno agricultor ou camponês é profundo, pois eles ganham a vida com ela e, por isso, conhecem 
bem a natureza. $\mathrm{O}$ autor conta que quando os corpos dos trabalhadores franceses doem de cansaço, eles dizem que seus ofícios formaram parte deles. "Para o trabalhador rural a natureza forma parte deles - e a beleza, como substância e processo da natureza pode-se dizer que a personifica" (TUAN, 1980, p. 111).

Este sentimento de fusão com a natureza não é simples metáfora. Os músculos e as cicatrizes testemunham a intimidade física do contato. "A topofilia do agricultor está formada desta intimidade física, da dependência material e do fato de que a terra é um repositório de lembranças [...]. A apreciação estética está presente, mas raramente é expressada" (TUAN, 1980, p. 111). Segundo este autor,

Para viver o homem deve ver algum valor em seu mundo. O agricultor não é exceção. Sua vida está atrelada aos grandes ciclos da natureza; está enraizada no nascimento, crescimento e morte das coisas vivas; apesar de dura, ostenta uma seriedade que poucas outras ocupações podem igualar. (TUAN, 1980, p. 113).

$\mathrm{Na}$ sociedade contemporânea emergem problemas complexos, de cunho social, ambiental e econômico, que transformam o dia a dia das pessoas numa corrida contra o tempo. Com isso, amplia-se a distância nas relações sociais, das relações consigo mesmo e com o universo. Talvez essa situação indique direções para mudar a maneira de pensar, ser e atuar no mundo, estabelecendo interações significativas, construindo outros modos de viver. Sob essa perspectiva, é necessário criar outras possibilidades de educação ambiental, para além das relações ecológicas e do sentido categórico de preservação, visando à construção de uma nova cidadania que retoma o ser humano no seu sentido integral, fortalecendo o sentimento de pertencimento planetário, através de uma perspectiva da dimensão humana entendida como parte do cósmico, conforme cita Rivaroli e Albernaz (2017).

A velocidade com que as mudanças vêm acontecendo reflete diretamente em insegurança e ansiedade. Isto justifica o grande número de pessoas com depressão na atualidade. Para Guattari (2015), o individualismo e a fraqueza das relações não deixam de ser problemáticas ecológicas e também são questões importantes para a educação ambiental que se compromete com as questões contemporâneas. A felicidade na contemporaneidade resume-se em "ter" e não em "ser". Para ele, "a subjetividade se encontra deste modo ameaçada de petrificação, perde a vontade pela diferença, pelo imprevisto, pelo acontecimento singular" (GUATTARI, 2015, p. 30).

Os meios de comunicação de massa diariamente preenchem o tempo com inúmeras informações e com grande velocidade, acabando por cancelar as possibilidades de experiência. Bondía (2002, p. 21) destaca que "nunca se passaram tantas coisas, mas a experiência é cada vez mais rara", seja por excesso de informação, de opinião, de tempo ou por excesso de trabalho, fazendo com que as pessoas, cada vez mais, assumam um papel passivo diante da vida. "A experiência é o que nos passa, o que nos acontece, o que nos toca. [...] A cada dia se passam muitas coisas, porém, ao mesmo tempo, quase nada nos acontece. [...]". A experiência, para este autor, remete e reforça além do modo de ser/viver experienciado, a necessidade do "momento de parada":

A experiência, a possibilidade de que algo nos aconteça ou nos toque, requer um gesto de interrupção, um gesto que é quase impossível nos tempos que correm: requer parar para pensar, parar para olhar, parar para escutar, pensar mais devagar, olhar mais devagar, e escutar mais devagar; parar para sentir, sentir mais devagar, demorar-se nos detalhes, suspender a opinião, suspender o juízo, suspender a vontade, suspender o automatismo da ação, cultivar a atenção e a delicadeza, abrir os olhos e os ouvidos, falar sobre o que nos acontece, aprender a lentidão, escutar aos outros, cultivar a arte do encontro, calar muito, ter paciência e dar-se tempo e espaço (BONDÍA, 2002, p. 5).

Para Bondiá (2002), no mundo contemporâneo tudo se passa muito depressa, de forma instantânea, pontual e fragmentada, não deixando vestígios de excitação ou alguma conexão significativa entre os acontecimentos. $\mathrm{O}$ autor ressalta a necessidade de um tempo mais lento para que o sujeito da experiência se faça pela sua própria existência, pela sua capacidade de formação ou transformação. Deste modo, pode sentir o emergir do saber da experiência, ou seja, pode sentir o modo como responde e dá sentido ao que lhe acontece no decorrer da vida. Afinal, "a experiência e o saber que dela deriva são o que nos permite apropriar-nos de nossa própria vida" (BONDÍA, 2002, p.27). Para Mendonça (2007), as experiências em meio à natureza permitem às pessoas ser como são, além de possibilitar às pessoas aflorar novos sentimentos em relação a si, aos outros e ao ambiente, oportunizando, dessa forma, um reconhecimento de suas responsabilidades perante os acontecimentos ao seu redor. 
No meio rural as pessoas têm uma relação mais estreita com a natureza, porém, o contato afetivo que elas têm com os recursos naturais e com as outras pessoas está se modificando. Presenciam-se cenários em que as famílias não mais visitam umas às outras, não participam da comunidade ou grupos sociais, e vivem relações cada vez mais frias em suas próprias casas. Essa situação não é característica apenas para quem vive no meio rural. Ao longo da história percebe-se que o ser humano deixou, paulatinamente, de se perceber como um ser complexo, deixando-se, muitas vezes, ser manipulado ao sabor das tendências, tornando-se apenas um ponto de referência estatístico imerso em uma cultura consumista, constituindo-se um subjetivo estereotipado (RÖHRS, 2020).

Guattari propõe pensar o homem enquanto um ser psíquico, envolvido e envolvente, e não como um objeto no ou do meio. "É a relação da subjetividade com uma exterioridade - seja ela social, animal, vegetal, cósmica - que se encontra assim comprometida numa espécie de movimento geral de implosão e infantilização regressiva. [...]" (GUATTARI, 1990, p.8) Para o autor, aquilo que pode ser dado como um avanço tecnológico é, na verdade, um caminho inverso para a sua sustentabilidade, de forma que os modos de vida humanos individuais e coletivos evoluem no sentido de uma progressiva deterioração. Tal fato pode ser interpretado como uma involução, pois, como afirma Guattari, "[...] não somente as espécies desaparecem, mas também as palavras, as frases, os gestos de solidariedade humana [...]" (GUATTARI, 1990, p. 27).

Para Guattari (1990), é necessário criar novos territórios existenciais, conceito que para o autor refere-se à articulação das três ecologias (da subjetividade, das relações sociais, do ambiente). Os territórios existenciais, para o autor, são capazes de se bifurcarem em reiterações que podem permitir que se torne habitável um projeto humano, ajudando a nortear os caminhos trilhados pela humanidade para o melhor desenvolvimento individual e coletivo, incorporando as questões ecológicas, sociais e morais de forma que mundos não se resumam a informações abstratas.

E segue: é necessário que se estabeleça um modo para que se reaprenda a ser humano novamente, para que se possa perceber o meio como um aliado parceiro e não apenas como um meio irrestrito de subsistência. Pois só assim, mudanças concretas podem tomar forma e auxiliar no melhor desenvolvimento da humanidade, de modo que não somente se vise o lucro e a produção desenfreada, mas que se produza de forma sustentável, a fim de que o próprio ser humano tome consciência de seu papel fundamental no melhoramento do presente para que o futuro seja possível, afirma.

Para Guattari (1990), a ecosofia anseia uma reapropriação da mídia pela multidão de sujeitos e grupossujeito capazes de gerir a máquina midiática em busca de uma ressingularização dos valores. Trata-se de ceder lugar às desterritorializações do social, pois a subjetividade instaura-se tanto no meio ambiente, nos agenciamentos do social e, ao mesmo tempo, nas mais desconhecidas paisagens do indivíduo, escreve Guattari. Importa, para ele, apreender o mundo a partir dos três vasos comunicantes que constituem três pontos de vista ecológicos formadores da ecosofia: ambiental, social e mental.

Ao pensar a educação ambiental com Guattari (2012) atenta-se para a complexidade contemporânea, em que o ambiente é entendido em sua interdependência com todos os fenômenos, sejam eles naturais, sociais ou mentais. As três ecologias estão sempre imbricadas. "Pensar com a ecosofia é acolher um pensamento múltiplo sem dar um juízo de valor, é se colocar junto ao problema que se enfrenta" (RIVAROLI; ALBERNAZ, 2017, p. 186).

Se colocar junto ao problema, vivenciar as relações socioambientais de forma mais profunda, instigam um novo processo de conhecimento. Ao conhecer, o sujeito se reconhece, e é nesse âmbito que se forma uma relação mais profunda deste sujeito consigo mesmo. Nesse contexto, as intervenções em educação ambiental, como se propõem nesta pesquisa-intervenção, constituem uma nova forma de olhar para si, olhar para o outro e olhar para o mundo, contribuindo para a formação de um novo paradigma, em confluência com novos sentidos e novos saberes.

\section{Método}

Os procedimentos metodológicos de abordagem adotados neste estudo têm como base a metodologia qualitativa, a pesquisa descritiva e explicativa, que buscam respectivamente apoiar-se nos significados dados pelas participantes à experiência, descrevê-la e identificar o que contribui para que ela aconteça.

Os procedimentos técnicos utilizados foram os estudos bibliográfico, documental e de campo. A pesquisa bibliográfica apoiou-se em livros e artigos científicos sobre os seguintes temas: mulheres rurais, educação ambiental e paisagem socioambiental. Documentos foram usados para caracterizar o contexto socioeconômico em que se inserem as mulheres participantes da pesquisa. $\mathrm{O}$ estudo de campo incluiu 
entrevistas individuais ao início e ao final do processo de coleta de dados; intervenções colaborativas de educação/sensibilização ambiental, observação direta e rodas de conversa em grupo focal.

A amostra foi constituída por um grupo de mulheres do município de Lagoão/RS, que residem no meio rural. Localizado na mesorregião Noroeste Rio-Grandense, o Município de Lagoão possui um dos menores Índices de Desenvolvimento Humano (IDH) do estado, uma área de 383,601 km² (EMATER, 2019a) e, segundo os dados do Censo Demográfico de 2018, tem 6.442 habitantes (IBGE, 2018). A agricultura familiar predomina no meio rural, em pequenas unidades de produção agrícola.

As mulheres rurais em questão participam ativamente de uma organização formal, com atividades periódicas planejadas anualmente. Estas atividades são organizadas pela extensionista rural social do escritório municipal da Emater/RS-Ascar de Lagoão e pelas presidentes dos grupos organizados de mulheres que integram a Associação Municipal das Trabalhadoras Rurais. As atividades visam promover a inclusão social, econômica e ambiental das mulheres por meio de ações coletivas municipais e regionais que buscam seu empoderamento, geração de renda na propriedade, promoção da saúde e qualidade de vida para as famílias.

Atualmente o município tem 13 grupos organizados com aproximadamente 300 mulheres participantes nas comunidades. Elas residem em pequenas propriedades rurais e atuam no que se denomina agricultura familiar, cultivando alimentos basicamente para o consumo da família com venda de excedentes. Algumas mulheres se destacam pela agroindustrialização caseira de alimentos, com os produtos sendo comercializados de maneira informal, outras mulheres cultivam alimentos para comercialização no Programa Nacional de Alimentação Escolar - PNAE e, com isso, também geram renda para a família. O principal produto gerador de renda destas famílias é o tabaco, sendo que em torno de $10 \%$ tem a soja como renda complementar (EMATER, 2019a).

Cerca de $20 \%$ das mulheres possuem baixa renda, enquadrando-se no grupo de famílias que cultivam apenas para subsistência e/ou sobrevivência, o que se carateriza por ser uma produção de alimentos em baixa escala, servindo apenas para a alimentação da família. Estas mulheres, em sua maioria, são beneficiárias do Programa Bolsa Família do Governo Federal, por meio do qual recebem um valor financeiro mensal para custear as despesas da casa, como alimentação e material escolar para os filhos (EMATER, 2019b).

Os grupos integram uma associação formal, a qual é denominada Associação Municipal das Trabalhadoras Rurais de Lagoão. Organizadas em grupos, são conhecidas no município devido à capacidade de liderança e organização. Com a organização das mulheres, gradualmente houve mudanças nas comunidades rurais e propriedades rurais, seja na infraestrutura física ou em relação às questões humanas, colaborando positivamente para o crescimento e melhoramento das mesmas.

Esta pesquisa foi desenvolvida com um dos grupos, composto por mulheres que aceitaram participar da pesquisa. Elas são da comunidade de Ronda Alta, onde participam 52 mulheres de faixa etária que varia entre 14 e 60 anos. Ronda Alta é uma comunidade que se localiza à $3 \mathrm{~km}$ da sede do município e possui o maior índice de famílias carentes do município. Foi realizada uma reunião de aproximação com o grupo de mulheres desta localidade, quando todas foram convidadas. Nove delas participaram da pesquisa e estiveram presentes em todos os encontros.

Os encontros aconteciam uma ou duas vezes na semana, durante os meses de agosto e setembro, dependendo da disponibilidade prévia de todas. Cada encontro era realizado na propriedade de uma das mulheres. O primeiro instrumento de coleta de dados utilizado junto ao grupo focal de pesquisa foram as entrevistas semi-estruturadas individuais, em agosto de 2019. Os temas das questões da entrevista individual inicial foram retomados de forma também individual, após as intervenções, em novembro de 2019, a fim de avaliar mudanças em relação aos elementos pesquisados. O guia das entrevistas iniciais e finais seguiu as categorias de análise definidas pelas dimensões da ecosofia: subjetividade, relações sociais e ambientais..

A essência do grupo focal consiste justamente na interação entre os participantes e o pesquisador, que objetiva colher dados a partir da discussão focada em tópicos específicos e diretivos (por isso é chamado grupo focal). Para Costa (2005), o grupo focal é uma metodologia qualitativa que pode gerar uma gama de informações extremamente ricas e significativas. "[...] o Grupo Focal, quando bem orientado, permite a reflexão sobre o essencial, o sentido dos valores, dos princípios e motivações que regem os julgamentos e percepções das pessoas" (COSTA, 2005, p. 180).

Os encontros de sensibilização foram planejados para proporcionar momentos de aprendizagem social, reflexão e relaxamento. Ao longo destes momentos de intervenção usou-se da técnica da observação direta, por ser uma estratégia que facilita a coleta de dados no campo: "é sem dúvida a técnica privilegiada para investigar os saberes e as práticas na vida social e reconhecer as ações e as representações coletivas na vida 
humana" (ROCHA; ECKERT, 2008, p. 2). Para as autoras, a observação a campo é uma aprendizagem para conhecer melhor o outro, ao mesmo tempo em que os pesquisadores conhecem melhor a si mesmos, pois requer que se participe no fluxo dos acontecimentos no espaço onde as pessoas vivem.

Os dados da pesquisa foram produzidos a partir de intervenções participativas, organizadas em forma de oito encontros de sensibilização, sendo um de aproximação e um de finalização, e os outros seis divididos nas três grandes categorias de análise: dois para questões subjetivas, dois para relações sociais e dois para relações com o ambiente. Todos os encontros mantinham a mesma estrutura, com uma pergunta sensível, atividade sensorial, atividade reflexiva, uma pergunta avaliativa. A Tabela 1, relativo ao segundo encontro, que tematizou as relações subjetivas, ilustra a estrutura (RÖHRS, 2020).

Tabela 1: Encontro 2 - Relações Subjetivas

\begin{tabular}{l}
\hline Pergunta poderosa: O que você valoriza em si mesmo? Por quê? \\
Tempo: 10 minutos \\
\hline Atividade sensorial: Mapa dos sons: Cada participante deverá encontrar um lugar confortável para se \\
sentar, não muito afastados uns dos outros. Então, deverão fechar os olhos e relaxar, escutando os sons \\
da natureza. Perguntar: Quais foram os sons ouvidos? O que esses sons lhes transmitiram? Qual a \\
sensação de sentir-se relaxado? O que seu entorno lhe transmitiu? \\
Tempo: 20 minutos \\
\hline Atividade reflexiva: \\
Solicitar (antecipadamente) que cada mulher leve consigo as cinco fotos as quais consideram mais \\
importantes na sua vida, que tenham em casa. Cada participante irá colocando as fotos no painel, e \\
explicando em ordem crescente o significado da mesma para sua vida. \\
Qual é sua história de vida? Que parte de sua história gostaria de compartilhar com o grupo? Das fotos \\
apresentadas, qual a mais representativa? Justifique. Quais são seus sonhos e prioridades? \\
O que mais gosta de fazer nas horas de lazer? \\
Me conte algo que te deixa realizada. \\
Tem alguma coisa que você desejava muito e já conquistou? \\
Tempo: 1 hora \\
\hline Pergunta poderosa: Como você está saindo hoje? \\
Tempo: 10 minutos
\end{tabular}

Os dados coletados ao longo da pesquisa de campo passaram pela análise textual que, segundo Moraes (2007), tem por finalidade descrever e interpretar os textos sobre o tema a ser pesquisado, no sentido de atingir uma compreensão mais elaborada dos discursos dos mesmos. Nesta pesquisa, o corpus foi formado pelos dados registrados sobre as observações e por meio das entrevistas e das transcrições dos encontros, quando ocorreram as atividades de sensibilização e as conversas com as mulheres rurais em suas propriedades.

Para Moraes (2007), a análise textual discursiva é descrita como um processo que se inicia com uma unitarização em que os textos são separados em unidades de significado, conforme os enunciados que o compõem. As unidades foram agrupadas a partir das categorias definidas a priori, ou seja, antes da pesquisa de campo iniciar, sendo elas: a) ecologia subjetiva; b) ecologia social; c) ecologia ambiental. As análises realizadas individualmente, quando reunidas, deixaram emergir as paisagens socioambientais coletivas ecosóficas.

\section{Paisagem socioambiental coletiva e os novos territórios existenciais}

As experiências vividas durante os encontros de educação ambiental criaram uma tessitura entre subjetividade, relações sociais e com o ambiente, que compuseram uma paisagem socioambiental coletiva e fizeram emergir novos territórios existenciais. Apresenta-se, agora, como se deu esta experiência ecosófica.

\subsection{Ecologia subjetiva}

Vivenciamos aceleradas mudanças na contemporaneidade, as quais comprometem a qualidade de vida das pessoas, e isso pode ser observado durante os encontros realizados com as mulheres rurais em suas propriedades. Quando Guattari (2015) cita que o individualismo e a fraqueza das relações não deixam de serem problemáticas ecológicas, ele reforça a necessidade de se inserir mais elementos da educação ambiental no contexto social. Através das intervenções realizadas, foi possível observar que as mulheres, na maioria das vezes, não se dão por conta da subjetividade que se encontra ameaçada pela velocidade e fluidez das relações em seu meio, mesmo quando caracteriza-se como rural e de um pequeno município do Rio 
Grande do Sul.

Isso ficou explícito quando algumas mulheres relataram que não tiravam tempo para cuidar de si ou visitar alguém para conversar. Afetada pelas rodas de conversas e pelas atividades vivenciais desenvolvidas a partir das intervenções, MG diz estar menos tímida, se abrindo mais com as pessoas e procurando sair mais de sua casa para passear. MA começou a tirar mais tempo para si e cuidar mais de sua saúde, pois como ela mesma disse "não tirava tempo nem para fazer exame". DZ contou alegremente que visitou uma irmã que morava longe e há muito tempo não via. ST, após as vivências, procura visitar mais sua mãe e conversar mais com as pessoas.

É esse contato mais íntimo consigo, com o outro e com o meio que desencadeia o que Bondía (2002) descreve como experiência, tudo aquilo que nos acontece, que nos toca e que, na maioria das vezes, passa no cotidiano como possibilidade de acontecimentos pouco percebidos. Os encontros tocaram de alguma forma as mulheres, tornando-as mais reflexivas sobre suas atitudes cotidianas, emergindo, assim, como experiência sensível. Um dos acontecimentos das intervenções que emergiu como uma experiência comum, que tocou a todas de forma especial, foi a construção da história de vida com a apresentação das cinco fotografias mais relevantes para cada uma. Conheceram-se mais a si mesmas e também uma a outra, percebendo que cada pessoa tem seus bons e difíceis momentos durante a vida. Nisso provocou-se uma experiência empática, consigo e com o outro.

Para a realização dessa atividade, que aconteceu no segundo encontro, havia sido solicitado previamente que as mulheres escolhessem fotografias importantes em sua vida, trazendo-as para contar um pouco de sua história. Em um painel, as mulheres iam colocando as fotos em ordem decrescente de importância e relatando estes fatos marcantes. Em seguida, escolhiam uma, entre as cinco fotografias, que considerasse mais representativa, para detalhar.

Essa atividade, ao mesmo tempo em que as emocionou pelo contexto de cada história, as fez desfrutar de um espaço protegido que se criou naquele momento, de amizade e confiança. A cada história contada a emoção era vivida por quem escutava e por quem narrava, remetendo a um cruzamento de trajetórias femininas. Retomar as suas histórias de vida por meio das imagens, que manifestaram também relações socioambientais, as fez aprender com a própria vivência, o que, como afirma Tuan (1983), é experienciar.

As atividades vivenciais e reflexivas provocadas pelas intervenções e provocadoras de aspectos subjetivos, sociais e ambientais, afetou cada uma de diferentes modos, mas a todas de uma forma que gerou um senso coletivo: DZ gostou de tirar fotos em meio a natureza, pois não tinha nenhuma foto dela sozinha, principalmente na cachoeira perto de sua propriedade, que ainda não conhecia. Foi oportunizado às mulheres, durante a trilha até a cachoeira (que aconteceu no sexto e no quarto encontros), a realização de algumas vivências em meio a natureza, em que puderam se fotografar de diversas formas: individualmente ou em grupos, fazendo diferentes poses, em cima de algumas árvores ou abraçadas a elas. Estas possibilidades exploradas livre e ludicamente as afetou. Nenhuma delas havia tido este tipo de experiência em sua vida adulta. Muitas delas não tinham fotografias de si mesma, sozinhas. Puderam, assim, perceberem-se diante de suas próprias imagens, observando-se. Visualizaram-se nos ambientes que vivem, no meio rural, onde cotidianamente constroem suas teias de vida, mas não se veem. Poder se ver as empoderou, atravessou sua subjetividade e faz algo aflorar.

Outra vivência que tocou várias delas, constituindo-se em uma experiência, entendida como aquilo que marca o corpo, foram as massagens. DZ foi especialmente afetada por esta prática, pois nunca havia tido este tipo de vivência. Elas aconteceram durante o terceiro encontro, quando as mulheres sentaram-se ao ar livre para alongarem-se e fazer massagens umas nas outras, como forma de relaxamento físico, mental e emocional.

Com as atividades vivenciais e reflexivas desarmaram-se emoções, o que afetou as relações sociais. MG relatou que adquiriu mais confiança em si mesma e, depois disso, encorajou-se e entrou em contato com sua mãe biológica, com quem desde a infância não interagia. Nesta retomada de uma conversa há muito retida como uma emoção dura, conseguiu uma explicação para o que há muito a fazia sofrer: por que fora abandonada quando criança. Uma energia foi reelaborada na psique desta mulher.

Essas transformações que emergiram a partir e durante as intervenções, vão ao encontro do que afirma Mendonça (2007): as vivências com a natureza possibilitam às pessoas aflorar novos sentimentos em relação a si, aos outros e ao ambiente. Isso ficou bastante perceptível tanto nas falas das mulheres durante a realização dos encontros, quanto na entrevista final. JO, por exemplo, relatou que passou a ser mais organizada, tira mais tempo para si, e, hoje, assume as atividades da comunidade com mais segurança e tem mais facilidade em liderar um grupo. ST chegou em casa do segundo encontro tão feliz e conversando além 
do habitual, que chamou atenção do seu marido. RS, que estava afetada por problemas de saúde na família, disse que se fortaleceu como mãe e esposa a partir das intervenções.

Ser mãe, priorizar os filhos e a família emergiu como um plano comum a todas as mulheres participantes dos encontros. Estes elementos, assim como são parte de seus sonhos, de suas felicidades e de seus objetivos de vida, ao tornarem-se suas prioridades, principalmente seus filhos, fizeram elas deixarem-se de lado em muitos aspectos. Com as vivências e as conversas reflexivas, perceberam que podem se incluir mais entre o que cuidam, para além da família, da propriedade, da casa e da comunidade.

O trabalho de care, como bem citado por Boris (2014), é visto pela sociedade como uma atividade natural do ser mulher, e para elas, não é diferente. O cuidado está impresso em suas tarefas diárias, e as mulheres veem isso de forma prazerosa e não como trabalho. Quando, a partir dos encontros, perceberam a necessidade de cuidarem de si, empreendendo ações efetivas para isso, algo aconteceu em suas vidas. Retomaram a si mesmas. A ecologia subjetiva reequilibrou-se um pouco mais. Adentraram algo novo em si mesmas.

\subsection{Ecologia social}

O diálogo que permeou o processo demonstrou ser uma ferramenta poderosa que permite o compartilhamento de saberes e a ressignificação de valores em cada tempo e contexto. Em cada tempo, porque a cada encontro uma mulher sentia-se mais à vontade para se abrir e falar sobre sua vida e seus relacionamentos socioambientais. Dependendo do contexto das rodas de conversas, elas se permitiram refletir e compartilhar suas experiências de vida, e com isso, reconhecerem-se como sujeitos atuantes no meio em que vivem.

Nenhuma pessoa consegue viver de forma isolada. Todos necessitam aprender a se relacionar com o outro, e isso é uma necessidade básica do ser humano. MA descreveu a relevância deste aspecto relacional ao citar que uma das dinâmicas, realizada durante o quinto encontro com o grupo, a impactou: quando todas tiveram que caminhar juntas, abraçadas, seguindo os mesmos passos. "Até na família da gente, nem sempre a gente consegue dar os passos sozinha, ou a gente precisa de um filho, ou precisa do marido, ou precisa da mãe, a gente sempre precisa de alguém".

Cada um nasce e cresce em um ambiente social, sendo o primeiro deles é a família. Entre os melhores relacionamentos citados por elas, este grupo social continua sendo o mais relevante, até mesmo pelas condições de vida que usufruem: ambientes rurais, comunitários, de pouca troca social além da comunidade base. Suas sociabilidades mais fundamentais são com seus familiares, principalmente marido e filhos, antes de qualquer outro grupo social.

A estrutura e as técnicas que compuseram os encontros demonstraram efetivamente que as intervenções permeadas pela proposta da educação ambiental ecosófica foram promotoras de fortes vínculos sociais e afetivos. Muitas delas relataram que estavam conversando mais, conseguiram se abrir uma com a outra, aprenderam a escutar mais, se colocando no lugar do outro. LB conta que o fortalecimento das amizades que vivenciou será algo que vai levar para toda sua vida, pois apesar de já conhecer as outras mulheres, nunca havia "parado" para conversar com todas elas.

Bondía (2002) aborda estes necessários "momentos de parada" no contexto social atual, onde os acontecimentos passam, muitas vezes, despercebidos: "parar para pensar", "parar para escutar", "falar sobre o que nos acontece", "cultivar a arte do encontro". As intervenções ecosóficas foram, certamente, um momento de parada para estas mulheres, para conversar sobre assuntos que, conforme disseram, jamais haviam conversado antes. DZ relatou que enquanto participava não pensava em "bobagens", o que demonstra que ampliar as oportunidades de encontros significativos na vida social, criando círculo de amizades, transmuta emoções, afetando os grupos de participação e a subjetividade de quem participa. ST relatou que a partir desse "momento de parada" e desses "momentos de conversas", conseguiu se "abrir" mais com seu marido e falar "eu te amo" para ele, o quê, por se dizer uma pessoa muito "fechada", sentia dificuldade em fazê-lo, mesmo que escutasse dele. Esta novidade na sua vida pode ser considerada com um salto afetivo importante. A intenção do processo de sensibilização ambiental não era terapêutica, mas a proposta ecosófica mostrou sua potência para a criação de novos territórios existenciais, conforme propõe Guattari.

Quando DZ disse que gostou muito de conhecer a propriedade rural de cada mulher e participar das atividades vivenciais, porque pode aprender e refletir sobre temas "importantes na vida da gente", ou quando JO relatou que aumentou seu envolvimento na comunidade, o qual já era bem frequente, e que com isso ganhava "paz de espírito", reforçaram que os processos educativos fortalecem as relações entre os 
envolvidos, como escreve Soares (2002).

A maioria das mulheres que compôs o grupo de intervenção já participava de coletivos de trabalhadoras rurais da comunidade, mas MG começou a participar incentivada pelos encontros. Ela relatou que gostou muito da dinâmica do Diagrama de Veen, realizada durante o quarto encontro com a finalidade de compreender a proximidade de cada mulher com diferentes grupos sociais. Nesta atividade, as mulheres utilizaram um cartaz, onde colaram a figura de uma pessoa no centro, representando a si mesma, e, ao redor, colavam figuras representativas de grupos sociais, mais perto ou mais distantes de si mesmas, conforme percebiam-se em relação a eles. As reflexões decorrentes desta atividade fizeram com que MG considerasse dedicar mais tempo ao grupo de trabalhadoras e na comunidade, pois percebeu que quase não saia de casa. Avaliou que tinha tempo e que a interação com outras mulheres era prazerosa. Uma novidade emergiu para ela, afetando seu território existencial. Portanto, com os encontros provocou-se, também, a formação do que Soares (2002) denomina como um ecossistema comunicativo, quando a comunicação intensifica as reflexões dentro de um grupo, de forma a contribuir para a superação de desafios e a ampliação de aprendizagens, gerando a colaboração e a percepção da interdependência das partes do grupo.

Mudanças de paradigmas melhoraram a vida social de cada mulher. RG, por exemplo, começou a participar mais da igreja/comunidade em consequência das intervenções realizadas. LB passou a frequentar mais os encontros do grupo de trabalhadoras rurais, porque é onde entende que aprende mais. JO, que é extremamente atuante na comunidade, relatou que saia dos encontros provocados pela pesquisa com ideias novas para aplicar com as pessoas da comunidade, pois gosta de ver as pessoas se sentirem bem com as ações que organiza, isto a deixa realizada. Freire (1988) é enfático ao escrever que a comunicação é um importante fator de mudança social e que, por meio dos processos educativos, pode-se formar novos sujeitos nos contextos sociais rurais, o que se evidenciou durante e após o desenvolvimento das intervenções desta pesquisa.

\subsection{Ecologia ambiental}

A ecologia ambiental pode ser caracterizada como uma nova relação do ser humano com a natureza e com tudo que constitui o meio em que vive. Mas para isso, como afirma Capra (1996), requer uma mudança nas percepções, nos pensamentos e de valores. Essas mudanças podem começar pela forma como se vê e se compreende o meio onde se vive.

Todas as mulheres participantes da pesquisa afirmaram gostar do lugar onde moram, principalmente pelo fato do ambiente rural ser mais tranquilo. JO relatou que quando sai para a cidade sente logo vontade de voltar para casa. Para MG o espaço onde construiu sua morada é o melhor lugar para se viver, tem um sentimento de amor por ele e jamais o trocaria. Esse sentimento de pertencimento ao meio, esse apego ao lugar onde vivem, remete a Tuan (1980, p.113), quando escreve que "para viver o homem deve ver algum valor em seu mundo". Ficou perceptível, durante o processo de pesquisa, que viviam nas propriedades mais organizadas e esteticamente mais elaboradas as mulheres que demonstraram serem mais felizes e valorizarem mais o meio rural.

Um dos temas que permeou a ecologia ambiental nos encontros foi o trabalho rural. Sua valorização ficou explícita quando MA relatou que gostava de morar no interior e de trabalhar na lavoura, quando JO afirmou ter prazer em plantar e colher para a alimentação da família ou quando MG contou que se realiza cuidando do pátio, principalmente dos canteiros de flores. Cada mulher, a seu modo, cria um valor para o lugar em que vive e o personifica, pois veem o ambiente como parte delas, como diz Tuan (1980). A topofilia do agricultor, mencionada por este mesmo autor, emergiu claramente durante as rodas de conversas, sendo expressa pelo afeto ao lugar onde vivem com suas famílias e pelas atividades que ali desenvolvem.

Afetividade e intimidade com a natureza podem ser mais percebidas por meio do contato feminino, segundo Garcia (2009), pois existe uma relação parecida entre as mulheres, a terra e a natureza. Durante as intervenções, indícios confirmaram o pressuposto desta autora. Em uma das vivências realizadas no oitavo encontro, ao serem convidadas a se compararem com um dos quatro elementos da natureza, cinco das nove mulheres se disseram mais parecidas com a Terra, por ser fértil e produtiva. Produtiva não só no sentido de produzir alimentos, mas também por produzir relacionamentos, amizades, afetos e diálogos. Ser fértil como a terra no sentido de ser forte, como disse MA: "ninguém é forte e fértil o tempo todo, mas também não podemos ser fracas, para quando aparecerem problemas, não sermos derrubadas por eles". Além de força, as mulheres expressaram, por meio desta reflexão comparativa, a sensibilidade que possuem em relação a natureza, o que foi perceptível durante os encontros e também foi trazida como uma característica com a qual se autodenominaram. 
Dentre as atividades realizadas pelas mulheres rurais em suas propriedades, está a produção de alimentos para o consumo da família. Conforme Herrera (2016), o trabalho realizado na horta, no pomar e o cuidado dos pequenos animais é reconhecidamente tarefa da mulher, onde há pouca ou nenhuma participação masculina. $\mathrm{O}$ que a autora coloca vai ao encontro ao que as mulheres relataram: JO tem a horta e o pomar como o que há de mais importante em sua propriedade, pois é dali que retira a alimentação da família. Na horta, seu filho mais velho, "ajuda quando não vai trabalhar". Conforme Paulilo (2013), as próprias mulheres veem as tarefas que as envolvem no entorno de suas casas, apenas como trabalho doméstico. Como cita esta mesma autora, "Se cuida da horta e das galinhas sozinha, é trabalho doméstico". DZ reforça essa afirmação quando disse que considera um entretenimento tratar as galinhas e os porcos.

Não podemos generalizar essa posição, pois exemplos de trabalhos conjuntos foram identificados nos relatos de RS e MD, que dividem as tarefas que são realizadas na propriedade, "até para fazer o almoço". Por outro lado, há a colaboração parcial também. JO contou que o marido faz o trabalho de casa somente quando ela não está. O marido de DZ já ajudou mais nas tarefas da casa, "hoje ajuda menos porque tem a menina".

As mulheres rurais realizam atividades nas lavouras tanto quanto seus maridos, o que mostra que seu trabalho não é restrito ao serviço doméstico ou de care, como também explica Neves e Medeiros (2013). MA prefere o serviço da lavoura do que a casa. LB também gosta mais do serviço "braçal" na lavoura, pois se sente mais livre. Todas relataram que trabalham na lavoura, mas o serviço "pesado" é do marido. Adentra-se aqui, em discordância com que Brumer (2004) escreve quando afirma que mesmo as mulheres trabalhando tanto quanto os homens, seu trabalho aparece como ajuda. Durante as conversas não foi detectado pensamento semelhante, pois sentem seu trabalho na lavoura reconhecido por toda sua família e pela sociedade onde estão inseridas, além disso dizem ter autonomia e entendem que assumem um protagonismo na propriedade, seja para o planejamento da produção como para gerenciamento da renda obtida, o que contradiz este mesmo autor, quando afirma que o crédito da produção agrícola é atribuído ao "chefe da família". Neste sentido, Herrera (2016) escreve que as mulheres agricultoras realizam atividades essenciais para a subsistência ou qualidade de vida da família, seja ela de importância biológica, social ou econômica, e que de certa forma, contribui para a preservação do meio ambiente.

Também foi utilizada a análise FOFA, a qual identifica Fortalezas, Oportunidades, Fraquezas e Ameaças em relação a algo. Esta dinâmica, desenvolvida durante o sétimo encontro, teve por finalidade especificamente provocar uma reflexão sobre as relações das mulheres com o trabalho rural, identificando as oportunidades e ameaças externas à propriedade rural, e reconhecendo as fortalezas e fraquezas que circundam o interior de uma propriedade e que permeiam o trabalho rural em diversos aspectos, como por exemplo, o trabalho na lavoura e na horta, a limpeza e o cuidado com a casa e com o pátio, o trabalho com os animais domésticos e o cuidado com a família. DZ relatou ter gostado muito da dinâmica, pois "falamos do serviço da gente, o que a gente faz no dia a dia”. MG e LB afirmaram que gostaram do tema porque é onde mais se envolvem no dia a dia: trabalho da lavoura, horta, casa, pátio e família. Ou seja, o cotidiano de trabalho está intrinsecamente relacionado ao ambiente, no entanto algumas mulheres demonstraram não usufruir do prazer do ambiente para além do trabalho, enquanto outras deleitam-se com a beleza das flores e a organização dos pátios, por exemplo.

Um outro aspecto em relação à ecologia ambiental refere-se ao fato que o trabalho de care, voltado para as necessidades físicas, intelectuais e afetivas dentro da família ou no círculo de convivência, como explica Boris (2014), não é visto pelas mulheres como trabalho, e sim como um componente natural realizado em conjunto com as atividades domésticas cotidianas. O cuidado com o outro está bastante imbricado no ser mulher e pode ser percebido quando abordamos as questões subjetivas, pois sempre priorizam os filhos e o marido. Portanto, como já mencionado anteriormente, quando se trata de afeto e de cuidado, as mulheres não tem preocupação com a sobrecarga de trabalho.

O cuidado não se restringe apenas ao contato com pessoas, mas também, com a natureza. No entanto, como explica Tuan (1980), na contemporaneidade, o contato das pessoas com a natureza é cada vez mais escasso e limitado, acontecendo uma vez ou outra em oportunidades pouco frequentes. A proposta de algumas vivências foi justamente isso, provocar um contato mais íntimo das mulheres com a natureza. DZ achou interessante a dinâmica do Mapa dos Sons, onde parou só para escutar os sons da natureza por vários minutos. Foi a primeira vez que fez isso na vida. Essa dinâmica, desenvolvida durante o segundo encontro, teve por objetivo provocar uma escuta atenta aos sons do ambiente natural, aguçando os sentidos e sensibilizando as mulheres para que, desta forma, conseguissem vivenciar o poder que os elementos naturais têm de deixar as pessoas mais relaxadas e atentas ao seu entorno.

O envolvimento suave com o mundo físico, que prevaleceu no passado, quando o ritmo da vida era mais lento, como exprime Tuan (1980), foi lembrado pelas mulheres quando estas relataram haverem tido mais 
contato com a natureza na sua infância do que na vida adulta. Na atualidade, disseram não tirar tempo para realizarem atividades assim. Por isso, as vivências proporcionadas nos encontros as sensibilizaram. LB adorou subir em árvores, o que não fazia desde sua infância. Tirar fotos em meio a natureza despertou um sentimento de alegria nas mulheres, pois não tinham imagens de si sozinhas, quanto mais em árvores ou em cachoeiras.

As fotos na natureza aguçaram o olhar sobre o meio onde vivem. ST ressignificou a paisagem do local do pomar, que antes não visitava. Passou a gostar e achá-lo mais bonito após olhar as fotografias. As vivências possibilitaram a ela ressignificar seu pomar. Como afirma Cabral (2007), "a paisagem percebida é também significada e construída". RS, por sua vez, ressignificou a paisagem da cachoeira de sua propriedade, tão próxima da casa, e não visitava. Após a trilha, realizada em um dos encontros, passou a levar sua filha de três anos, que não conhecia, e agora cobra este passeio da mãe. A beleza das fotografias que RS visualizou da cachoeira a fez rever sua relação com paisagem de sua propriedade, passando a admirá-la.

Como os encontros aconteciam nas propriedades rurais das mulheres envolvidas nesta pesquisa, várias leituras foram feitas em relação a cada paisagem observada. MA, por exemplo, se entusiasmou com as paisagens observadas em cada lugar, o que afetou o modo de cuidar do ambiente de sua propriedade. MD está procurando deixar mais organizado o ambiente onde vive. ST não gostava de ir na horta e passou a gostar mais após a realização dos encontros, do qual decorreu uma nova "leitura" do seu lugar. Como diz Tuan (1983, p. 150), "a paisagem pode ser considerada um texto que serve a uma multiplicidade de leituras".

\section{Considerações sobre a paisagem socioambiental ecosófica coletiva}

Em síntese, como elementos constituintes de novos territórios existenciais para este grupo de mulheres, que Guattari (1990) caracteriza como novos modos de vidas humanos individuais e coletivos decorrentes da articulação das três ecologias, identificamos: a) como elementos subjetivos: a percepção da necessidade de investir no autocuidado, a emersão de novos sentimentos de amizade e confiança pelo outro, maior empoderamento e organização pessoal; b) como elementos sociais destacaram-se: aproximações nas relações familiares, ampliação na interação comunitária, fortalecimento das amizades, surgimento e reconhecimento da empatia e manifestação de novos paradigmas sobre convívio social; c) como elementos ambientais: a ressignificação do espaço da propriedade, modificando o modo de cuidar da mesma, mais organização e melhoramento do entorno, o sentimento de pertencimento ao meio, excitação dos sentidos, criando, com isso, maior sensibilidade ao contato com a natureza.

As atividades vivenciais desenvolvidas foram fundamentais para que cada mulher se percebesse em seu mundo como quem faz sua história, onde pode continuamente criar novas possibilidades existenciais. As experiências vividas no ambiente organizaram-no e geraram autoorganização, transformaram-no e geraram autotransformação. Por meio do contato algo as tocou. À medida que iam percebendo mais a si mesmas e às outras também o faziam em relação à paisagem física. Paisagens externas e internas foram concomitantemente sendo ressignificadas por meio do afeto e dos laços integrativos (TUAN, 1983; COSGROVE, 1998; CABRAL, 2007).

Pelos modos de ver, viver, fazer e se relacionar, os espaços internos e externos foram sendo significados e transformados em lugar a partir das relações que se teceram entre as ecologias subjetiva, social e ambiental, que reelaboraram o território rural, assim como os territórios existenciais (GUATTARI, 1990; OLIVEIRA, 2000). Ficou bastante evidente que "falar da paisagem é falar de nós mesmos" (CARVALHO, 2011, p. 38).

As paisagens socioambientais são construções em movimento. São inapreensíveis, pois é o que se vive (MONBEIG, 2005; SALVADOR, 2008). Com alegria e, talvez, alguma melancolia, novos territórios existenciais emergiram a partir da articulação das três ecologias exploradas nos encontros de educação ambiental ecosófica criados pelas pesquisadoras, que provocaram cada mulher a reconhecer suas próprias paisagens socioambientais individuais e a reconhecer as paisagens das outras, imprimindo na sua a paisagem socioambiental ecosófica coletiva que viveram juntas. Acessando a si mesmas, acessaram às outras e ao que permeia todas. Acessaram vida.

A paisagem é parte do corpo dessas mulheres, que estava um pouco esquecida, que foi rememorada com os encontros provocados pela educação ambiental ecosófica. Relembraram o contato primordial consigo e com a natureza ao se juntarem em grupo, por meio do qual acessarem um plano comum. Retomando a paisagem incorporada, reinventaram-se um pouco. Algo as tocou: uma massagem, uma caminhada coletiva, os sons da natureza mapeados no silêncio, as fotografias da vida, a imagem de si nos seus lugares, a escuta da outra. Estes toques, antes inesperados, as abriu para novas possibilidades ou velhas possibilidades esquecidas de si mesmas. Um devir mulher-natureza foi experienciado. 
Notas

Este artigo é parte integrante da dissertação de mestrado da primeira autora, intitulada Mulheres rurais e suas relações com a paisagem socioambiental: experiências ecosóficas, no Programa de Pós-Graduação Ambiente e Desenvolvimento, da Universidade do Vale do Taquari, sob orientação da segunda autora.

\section{Referências}

BONDÍA, J. L. Notas sobre a experiência e o saber de experiência. Revista Brasileira de Educação, n. 19, 20-28, jan./abr. 2002. DOI: https://doi.org/10.1590/S1413-24782002000100003

BORIS, E. Produção e Reprodução, casa e trabalho. Revista Tempo Social, v. 26, n. 1, 101-121, 2014. DOI: https://doi.org/10.1590/S0103-20702014000100008

BRUMER, A. Gênero e agricultura: a situação da mulher na agricultura do Rio Grande do Sul. Revistas de Estudos Feministas, v. 2, n. 1, 205-227, jan./abr. 2004. DOI: https://doi.org/10.1590/S0104026X2004000100011

CABRAL, L. O. Revisitando as noções de espaço, lugar, paisagem e território, sob uma perspectiva geográfica. Revista de Ciências Humanas, v. 41, n. 1, 141-155, abr./out. 2007. DOI: https://doi.org/10.5007/\%25x

CAPRA, F. A teia da vida: uma nova compreensão científica dos sistemas vivos. São Paulo: Cultrix; 1996.

CARVALHO, D. R. A valoração da paisagem: uma reflexão do espaço concebido, percebido e vivido. 2011. Tese (Doutorado em Geografia) - Núcleo de Pós-Graduação em Geografia, Pró-Reitoria e PósGraduação em Pesquisa, Universidade Federal de Sergipe, São Cristóvão, 2011.

CORRÊA, R. L.; ROSENDAHL, Z. Apresentando leituras sobre paisagem, tempo e cultura. In: Corrêa, R. L.; Rosendahl, Z. Paisagem, tempo e cultura. Rio de Janeiro: Editora UERJ; 1998. p. 7-11.

COSGROVE, D. A Geografia está em toda parte: cultura e simbolismo nas paisagens humanas. In: Rosendahl, Z.; Corrêa, R. L. Paisagem, tempo e cultura. Rio de Janeiro: Editora UERJ; 1998. p. 92-123.

COSTA, M. E. B. Grupo focal. In: Duarte, J.; Barros, A. Métodos e técnicas de pesquisa em comunicação. São Paulo: Atlas; 2005. p. 180-192.

EMATER. Rio Grande do Sul - ASCAR. Estudo de situação da EMATER. Disponível em: <http://www.emater.tche.br>. Acesso em: 12 jan. 2019a.

EMATER. Rio Grande so Sul - ASCAR SISPLAN - Sistema de Registro Informatizado do Planejamento. Disponível em: <http://www.emater.tche.br.> Acesso em: 12 jan. 2019b.

FREIRE, P. Extensão ou comunicação? Rio de Janeiro: Paz e Terra; 1988.

GARCIA, L. A relação mulher e natureza: laços e nós enredados na teia da vida. Gaia Scientia, v. 3, n. 1, 11-16, jun. 2009.

GOMES, R. de C. M.; NOGUEIRA, C.; TONELI, M. J. F. Mulheres em contextos rurais: um mapeamento sobre gênero e ruralidade. Psicologia \& Sociedade, v. 28, n. 1, 115-124, 2016. DOI: https://doi.org/10.1590/1807-03102015v28n1p115

GUATTARI, F. As três ecologias. 11. ed. Campinas: Papirus; 1990.

GUATTARI, F. Caosmose: um novo paradigma estético. 2. ed. São Paulo: Editora 34; 2012.

GUATTARI, F. ¿Qué es la ecosofía?: Textos presentados y agenciados por Stéphane Nadaud. Buenos Aires: Cactus; 2015.

HERRERA, K. M. Da Invisibilidade ao Reconhecimento: mulheres rurais, trabalho produtivo, doméstico e 
de care. Política \& Sociedade, v. 15, 208-233, 2016. DOI: https://doi.org/10.5007/21757984.2016v15nesp1p208

IBGE - Instituto Brasileiro de Geografa e Estatística. Número total de mulheres da população brasileira. Disponível em: <http://www.ibge.gov.br/>. Acesso em: 12 de mar. 2018.

LOUREIRO, C. F. B. Educação Ambiental Transformadora. In: Layrargues, P. P. (Org.). Identidades da educação ambiental brasileira. Brasília: MMA; 2004. p. 65-84.

MENDONÇA, R. Educação ambiental vivencial. In: Júnior Ferraro, L. A. Encontros e caminhos: formação de educadoras (es) ambientais e coletivos educadores. Vol. 2. Brasília: MMA, Departamento de Educação Ambiental; 2007. p. 118-129

MOMBEIG, P. A paisagem, espelho de uma civilização. In: Dantas, A. Pierre Monbeig: um marco da Geografia brasileira. Porto Alegre: Sulina; 2005. p. 116-127.

MORAES, R. Mergulhos discursivos: análise textual qualitativa entendida como processo integrado de aprender, comunicar e interferir em discursos. In: Galiazzi, M. do C.; Freitas, J. V. Metodologias emergentes de pesquisa em educação ambiental. Ijuí: Unijuí; 2007. p. 85-114.

NEVES, D. P.; MEDEIROS, L. S. Mulheres camponesas: trabalho produtivo e engajamentos políticos. Niterói: Alternativa; 2013.

OLIVEIRA, L. de. Percepção da paisagem geográfica: Piaget, Gibson e Tuan. Geografia, v. 25, n. 2, 5-22, ago. 2000.

PAULILO, M. I. S. FAO, fome e mulheres rurais. Dados - Revista de Ciências Sociais, v. 56, n. 2, 2013. Disponível em: < https://www.scielo.br/scielo.php?script=sci_arttext $\pi \mathrm{d}=\mathrm{S} 0011$ $52582013000200002 \& \operatorname{lng}=$ pt\&tlng=pt $>$. Acesso em: 10 dez. 2018.

RIVAROLI, A. P. dos S.; ALBERNAZ, R. M. A educação ambiental e a proposta Ecosófica. Uma micropolítica no cenário contemporâneo. Revista Eletrônica do Mestrado em Educação Ambiental, v. 34, n. 2, 173-189, mai./ago. 2017. DOI: https://doi.org/10.14295/remea.v34i2.7022

ROCHA, A. L. C. da; ECKERT, C. Etnografia: saberes e práticas. Iluminuras, v. 9, n. 21, 1-23, 2008. DOI: https://doi.org/10.22456/1984-1191.9301

RÖHRS, Viviane. Mulheres rurais e suas relações com a paisagem socioambiental: experiências ecosóficas. 2020. Dissertação (Mestrado) - Curso de Ambiente e Desenvolvimento, Universidade do Vale do Taquari - Univates, Lajeado, 24 jun. 2020. Disponível em: <http://hdl.handle.net/10737/2874>.

SALVADOR, D. Das perspectivas técnicas e supra-orgânicas às representacionais: breves reflexões sobre as abordagens geográficas acerca da cultura. Holos, v. 2, 27-44, 2008 . DOI: https://doi.org/10.15628/holos.2008.112

SAUER, C. O. A morfologia da paisagem. In: Rosendahl, Z.; Corrêa, R. L. Paisagem, tempo e cultura. Rio de Janeiro: Editora UERJ; 1998. p. 12-74.

SOARES, I. de O. Gestão comunicativa e educação: caminhos da Educomunicação. Comunicação \& Educação, n. 23, 16-25, jan./abr. 2002. DOI: https://doi.org/10.11606/issn.2316-9125.v0i23p16-25

TUAN, Y. Espaço e lugar. São Paulo: Difel; 1983.

TUAN, Y. Topofilia. São Paulo: Difel; 1980.

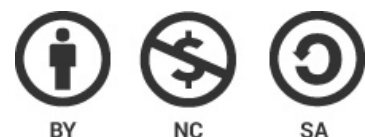

Este artigo é distribuído nos termos e condições do Creative Commons Attributions/AtribuiçãoNãoComercial-CompartilhaIgual (CC BY-NC-SA). 